\title{
NUMERICAL AND ANALYTICAL EVALUATION OF CONTINUOUS CONCRETE BEAM REINFORCED WITH FRP BARS
}

\author{
Aya Belal \\ Civil Engineering Department, German University in Cairo (GUC), \\ New Cairo, Egypt \\ Amr Elnemr \\ Civil Engineering Department, German University in Cairo (GUC), \\ New Cairo, Egypt \\ Nagy F.Hanna \\ Civil Engineering Department, German University in Cairo (GUC), \\ New Cairo, Egypt
}

\begin{abstract}
An innovative promising non corrosive material to be used in reinforcing concrete structures has emerged; which is the Fiber Reinforced Polymers. It has been used as replacement for conventional steel reinforcement for several concrete structural members. Yet, some of these structural members have not been studied intensively, such as continuous beams. Continuous beams as structural elements might exist in residential, commercial buildings as well as bridges. This paper uses the continuous beam element to investigate the predicted equations for the crack widths and the deflection at the serviceability limit state SLS assigned by various codes and guidelines, a finite element model was established using ANSYS software. This model was validated against the experimental work done by El-Mogy,M. (2011) which is the foundation of this research.

Various codes were adopted to estimate the deflection and the crack width against the verified ANSYS model to distinguish if any further modifications are required. The used codes in this study are the Egyptian Code of Practice ECP, the American Concrete Institute ACI guidelines and the Canadian Standards Association CSA.

It was found that the American and the Canadian codes produced approximately the same results in the crack widths while modifications should be done in the Egyptian code in order to be used in designing structures and perform as the other ones that are similar to reality; it yielded a percentage of variance of more than 50 percent than the other codes which is an unacceptable percent while in the deflection calculations, nonsatisfactory results were conducted from all the used codes in this study with maximum
\end{abstract}


variance of $200 \%$ yielded by the Canadian code; the results were precise but not accurate when compared to the ANSYS model.

Keywords: ACI, ANSYS, Continuous beam, CSA, ECP, FRP bars

Cite this Article: Aya Belal, Amr Elnemr and Nagy F.Hanna, Numerical and Analytical Evaluation of Continuous Concrete Beam Reinforced with FRP Bars, International Journal of Civil Engineering and Technology (IJCIET), 12(4), 2021, pp. 1-20. https://iaeme.com/Home/issue/IJCIET?Volume=12\&Issue $=4$

\section{INTRODUCTION}

Steel reinforcement corrosion has been a major drawback when used in as reinforcement in reinforced concrete members. Total deterioration occurs in the concrete structures, especially when exposed to high corrosive environment; this may result in strengthening and repair of the concrete structure building which is usually cost effective. Several attempts have been made to innovate new material that can sustain the corrosion such as epoxy coated steel reinforcement, galvanized steel reinforcement etc. However, the problem was still existing due to the limitation in these innovative reinforcements. For instance; the epoxy coated steel reinforced was noticed to be suffering from concentrated corrosion when exposed to corrosive environments. This concentrated corrosion results in cutting off the reinforcement length instead of reducing the cross sectional area as in conventional reinforcement. Thus, a significant amount of research has been done by using the newly developed FRP bars compensating the corrosion problem associated with the steel reinforcement due to its non-corrosive nature. Since then, the FRP has started gaining significant support as reinforcing bars and strengthening structural elements.

Several design codes and guidelines have been developed from around the world for the use of FRP as a reinforcement material (Prince 2017), three codes have been chosen in this study; the Egyptian Code of Practice ECP, the American Concrete Institute ACI guidelines and the Canadian Standards Association CSA.

In this paper, the study is focused on establishing a model using ANSYS software to simulate the behavior of indeterminate continuous beams reinforced with FRP bars. Comparison between the codes is done to ensure the serviceability limit states were achieved at its best; crack widths and deflections are calculated in each code and compared together with the validated ANSYS model. Serviceability state is of concern when reinforcing with FRP bars due to their lower modulus of elasticity with respect to the steel bars.

The study investigated, also, the validation and whether modifications should be implemented on the chosen codes and guidelines equation after evaluating the existing ones. Thus, the main objective of this research is to highlight for the practitioners the methods applicable when dealing with the continuous beam reinforced with FRP bars.

\section{TEST SPECIMEN}

To achieve the aforementioned objective, an experimental work form the literature was adopted in this research. Herein, in this paper, the model was validated by the experimental work tested by (ElMogy et al. 2010). The experimental program consists of two beams; each one was reinforced with different type of FRP bars. The FRP bars used were CFRP and GFRP reinforcing bars. The material properties and detailed specimens are presented in TABLE (1) and (2).

The Canadian code recommends for a beam reinforced with FRP bars to fail by compression and that was the concept used behind designing those beams, a Tensile strength of $2.7 \mathrm{MPa}$ and an average Compressive strength of $26 \mathrm{MPa}$ are the strengths of the used concrete after doing compressive and splitting tests on standards concrete cylinders (El-Mogy, M. 2011). 
Tensile tests were done on the representative specimens to produce the mechanical properties of the used Glass and Carbon reinforcing bars with respect to the ACI code (ElMogy, M. 2011).

Table 1 Reinforcement details (El-Mogy, M. 2011)

\begin{tabular}{|c|c|c|c|c|c|}
\hline Beam & Bar type & \multicolumn{2}{|c|}{ Top reinforcement } & \multicolumn{2}{c|}{ Bottom reinforcement } \\
\hline CS/e & CFRP & 4 No.10 & $0.56 \%$ & 3 No.10 & $0.42 \%$ \\
\hline GS/e & GFRP & 3 No.16 & $1.18 \%$ & 2 No.16 & $0.79 \%$ \\
\hline
\end{tabular}

Table 2 Mechanical properties of the reinforcing bars (El-Mogy,M. 2011)

\begin{tabular}{|l|c|c|c|c|c|}
\hline Bar type & $\begin{array}{c}\text { Bar diameter } \\
(\mathbf{m m})\end{array}$ & $\begin{array}{c}\text { Bar Area } \\
\left(\mathbf{m m}^{\mathbf{2}}\right)\end{array}$ & $\begin{array}{c}\text { Modulus of } \\
\text { elasticity }(\mathbf{G P a})\end{array}$ & $\begin{array}{c}\text { Tensile strength } \\
(\mathbf{M P a})\end{array}$ & Ultimate Strain \\
\hline Stirrups & 8 & 49.4 & 190 & $\mathrm{f}_{\mathrm{y}}=300^{*}$ & $\varepsilon_{\mathrm{y}}=0.0016^{*}$ \\
\hline GFRP & 15.9 & 198 & $46 \pm 1$ & $731 \pm 9$ & $0.016 \pm 0.0005$ \\
\hline CFRP & 9.5 & 71 & $116 \pm 2$ & $1388 \pm 62$ & $0.012 \pm 0.0007$ \\
\hline
\end{tabular}

Fig. (1) shows the detailed specimen dimensions, cross section, instrumentation and test setup procedure considered while testing. The reinforced concrete beams used in this study have a rectangular cross section of dimensions $(200 \times 300) \mathrm{mm}$; the beams are continuous over two spans of $2.8 \mathrm{~m}$ each and a total length of $6.0 \mathrm{~m}$. It should be mentioned that both beams were reinforced transversely with steel stirrups. The Finite element model was established based on several entries from material properties, cross section dimension and test setup procedure which is represented in the following sections.

The beams used here in this study are as follows; CS/e donated for a continuous beam reinforced with top and bottom longitudinal Carbon Fiber Reinforced Polymers without permissible moment redistribution. Similarly, for a continuous beam reinforced with Glass Fiber Reinforced Polymers bars without permissible moment redistribution is donated by GS/e.

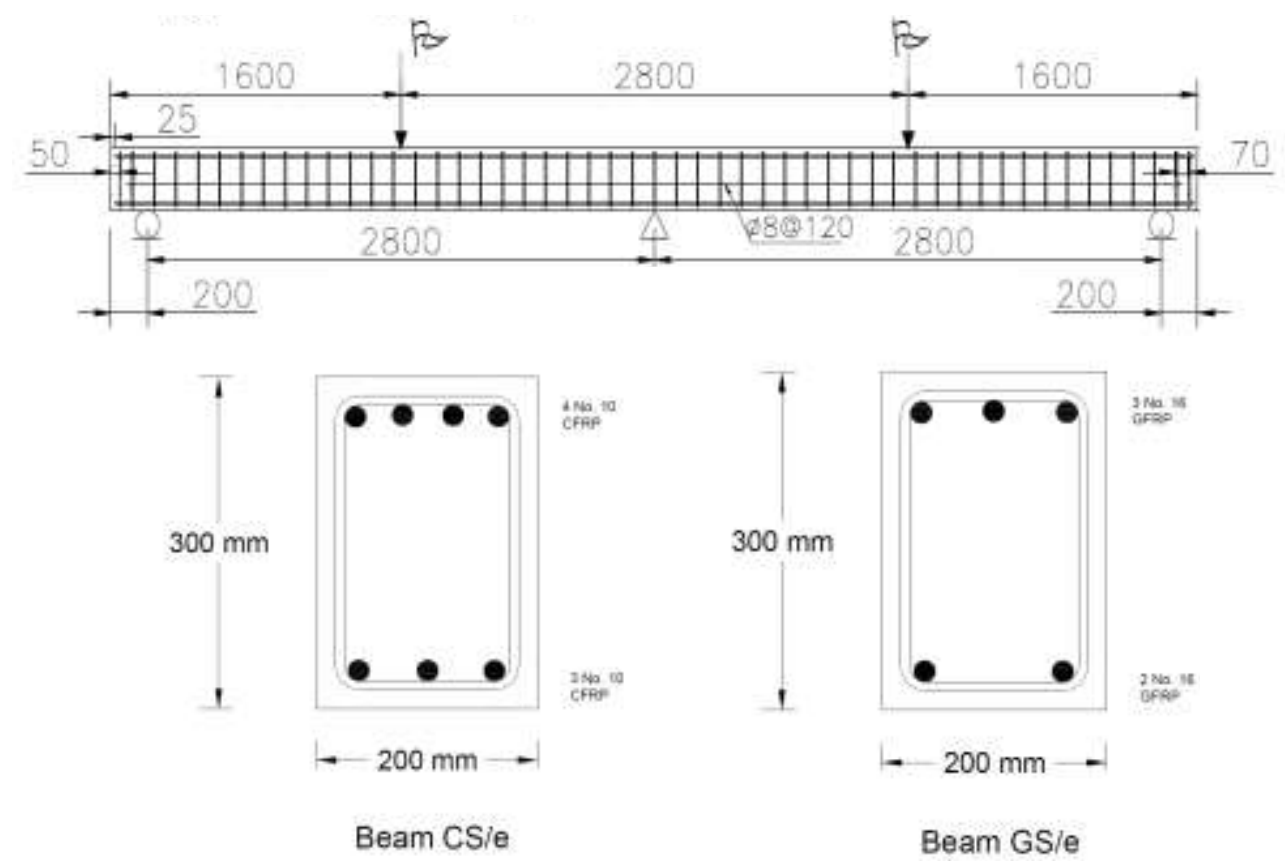

Figure 1 Details of the tested beams (El-Mogy, M. et.al 2010) 


\section{ANSYS MODELS}

To simulate the flexural behaviour of the continuous concrete beams reinforced with FRP bars; a finite element package ANSYS (2015) is used. The model is conducted to have a mesh size of $20 \mathrm{~mm}$ after several trails to maintain the optimum converges that ANYSYS can achieve. Firstly, the model is validated using the experimental work done by ElMogy (2011) for a continuous beam reinforced with FRP bars. The beam was loaded at the mid-span, as shown in Fig. (2).

SOLID65 is used to model the concrete on ANSYS 2015 as this solid element accounts for the material non-linearity, it is divided into two parts; linear isotropic and multi linear isotropic properties which suitably describes the concrete.

LINK180 is used to model the longitudinal FRP reinforcing bars and the Steel stirrups as it can represent plastic deformation and non- linearity of the elements; linear elastic model is used for the FRP bars since their stress strain curve is linear while for the steel stirrups, Bi linear isotropic is used to model them.

SOLID45 is used for the steel bearing plates that are located at the supports and the loading points having modulus of elasticity of $200,000 \mathrm{MPa}$ and Poisson's ratio of 0.3 , only linear elastic behaviour is customized for the steel bearing plates ignoring any nonlinear behaviour which should never be conquered.

Due to the lack of information regarding the bond behaviour and to validate the model with those tested beams by (ElMogy 2011); the bond behaviour between the FRP reinforcing bars and the surrounding concrete is assumed to be prefect. Nevertheless, various data are available in the field representing the bond-slip relationship between the FRP bars and concrete through pullout testing have been conducted by several researchers. In this paper, the bond behaviour between the FRP reinforcing bars and concrete is not the scope. The bond between the FRP and the surrounding concrete is assumed to be a perfect bond. Finally, the model is assigned to fail in concrete crushing. Therefore, the concrete strain should reach its maximum compressive strain of $3000 \mu \varepsilon$ as adopted by ECP 203 (2007) and ACI 440.1R (2015). It is noticed that the span of the continuous beam is equal in length which assimilate the use of symmetrical option to reduce the computational time when using the ANSYS.

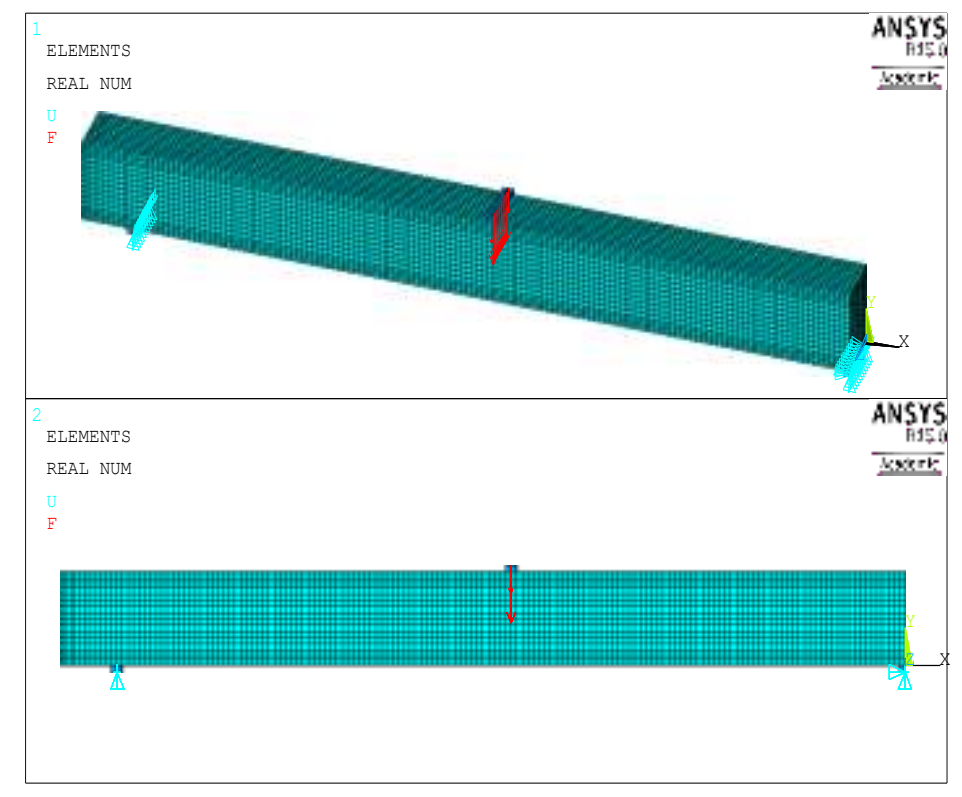

Figure 2 Meshing, Load and Boundary Condition for all the beams 
Aya Belal, Amr Elnemr and Nagy F.Hanna

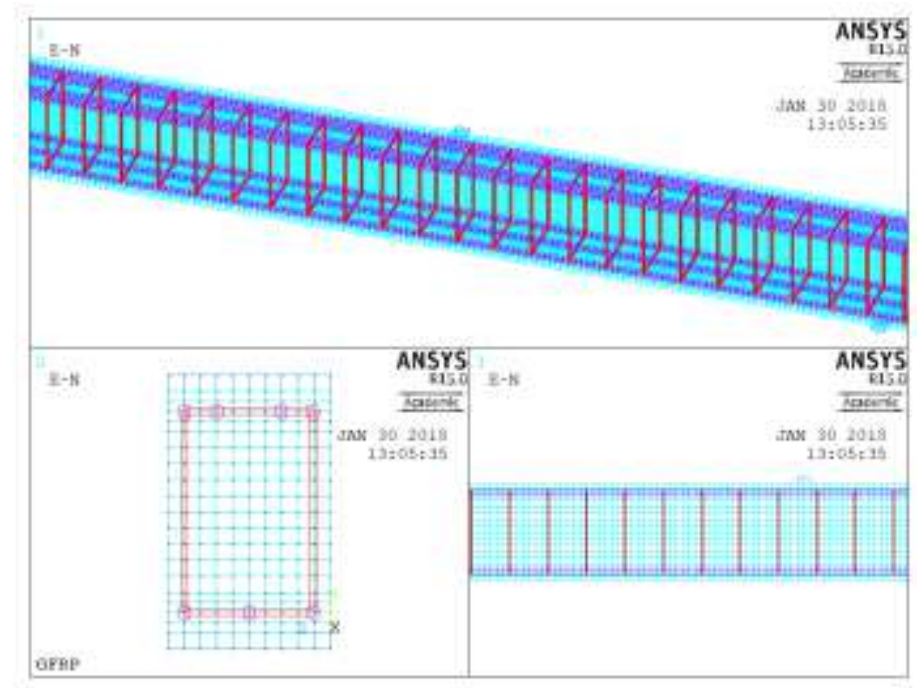

Figure 3 Multiple views of beam CS/e

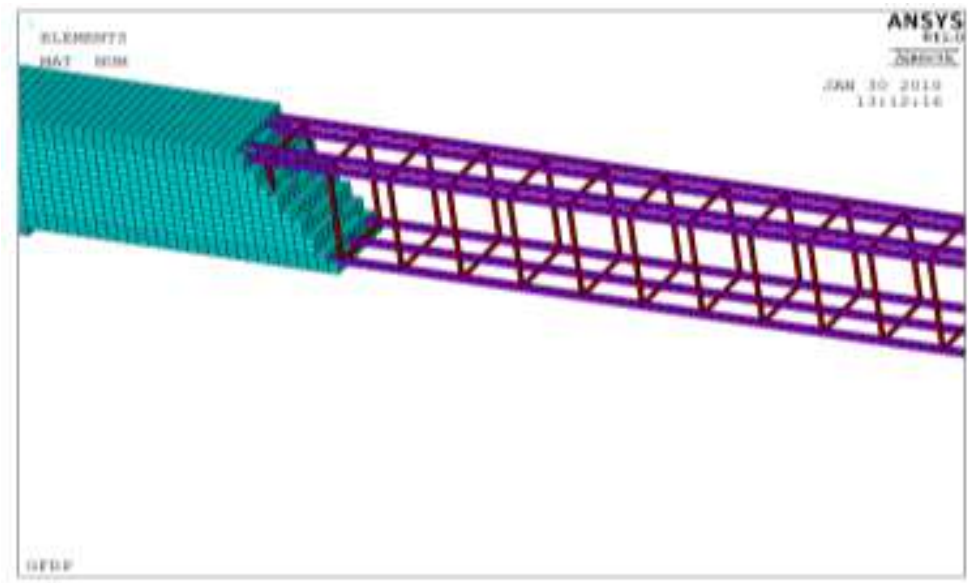

Figure 4 Details of the reinforcement of CS/e

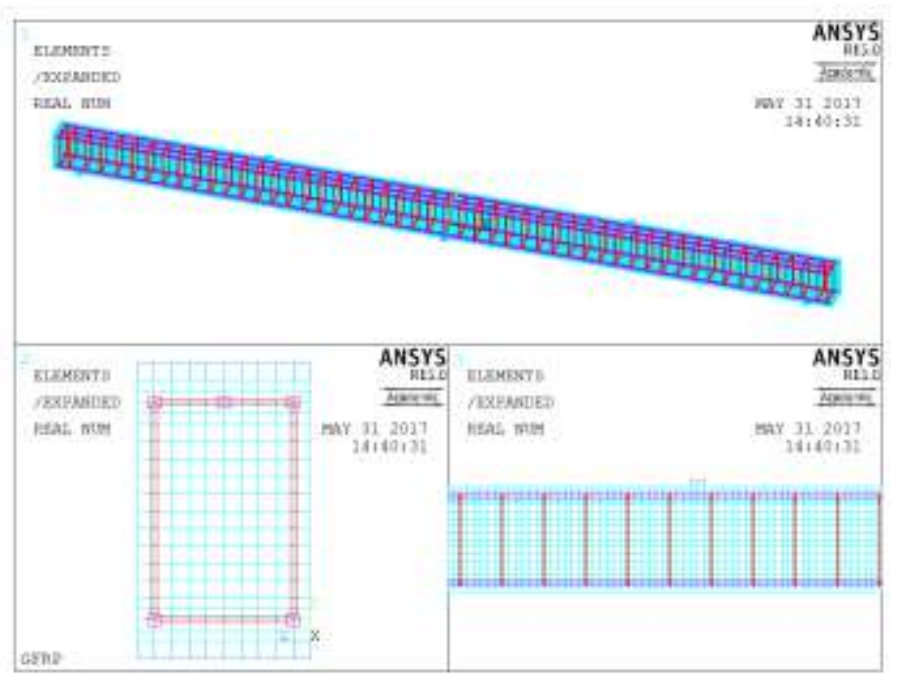

Figure 5 Multiple views of beam GS/e 


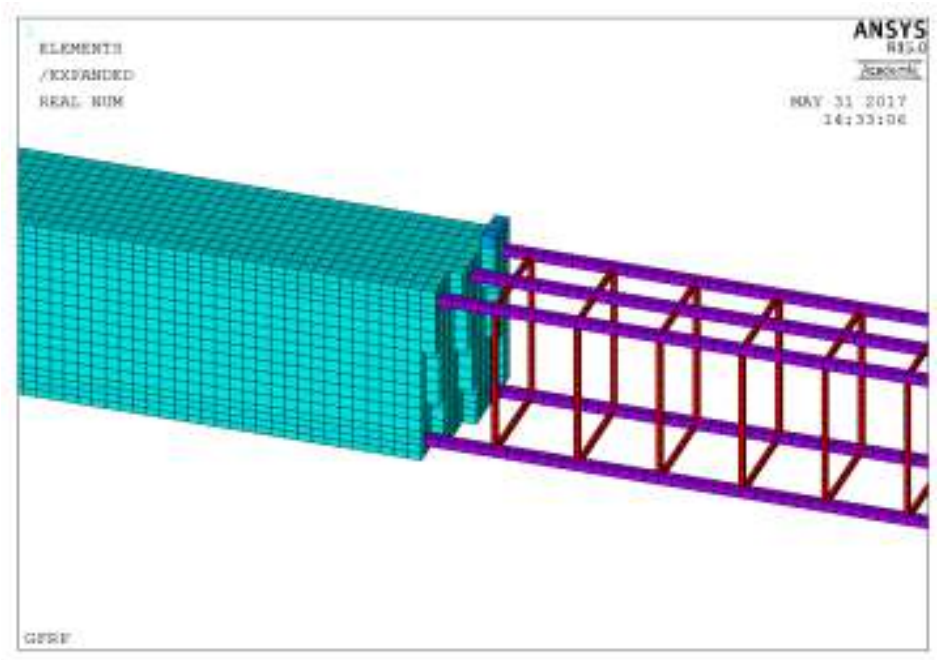

Figure 6 Details of the reinforcement of GS/e

\subsection{Validation}

The model is validated against the experimental test results provided by ElMogy (2011). The validation accounted for the strain in reinforcement at the mid-span and middle support, midspan deflection and finally; crack pattern at the top middle support and bottom mid-span of continuous beam is acquired along with the tested beams. The next upcoming section introduced the validation and variation between the experimental results and those resulted from modelling.

\subsubsection{Validation of CS/e}

\subsubsection{Crack pattern}

The cracks in any ANSYS model are shown as a collection of circles and octrahedron with different colors as shown in Fig.(7) after zooming in into the cracks that appeared in Fig. (11), each shape has its own meaning; the circle represents the plane of the crack while the octahedron shows the location of crushing. If a crack has opened then closed, the circle outline will have an $X$ through it. The red color represents the first crack, the second crack is shown with a green outline and the third crack is the blue one (ANSYS 2015).

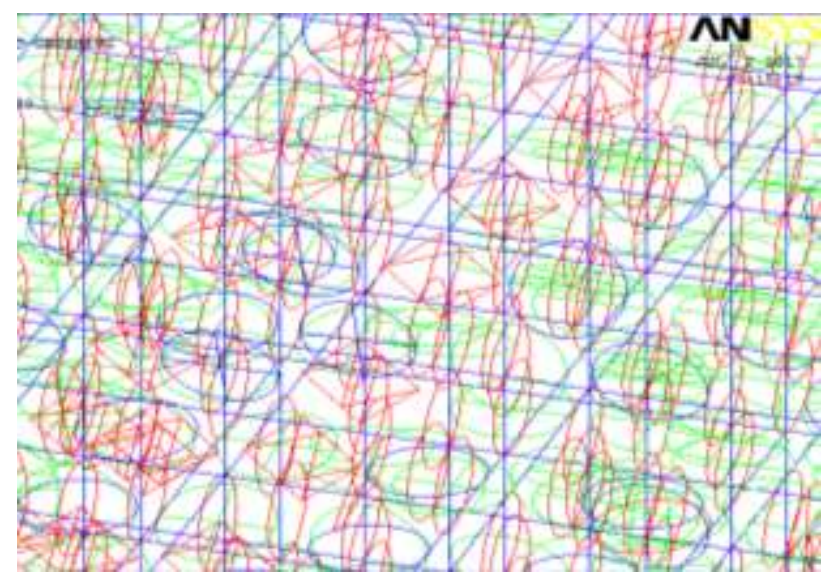

Figure 7 Cracks' details

The experimental work stated that the first crack appeared at a load of $20 \mathrm{KN}$ then the cracks started to increase as the load step increased, the following figures will show the cracks that appeared at $20 \mathrm{KN}$. 
Aya Belal, Amr Elnemr and Nagy F.Hanna

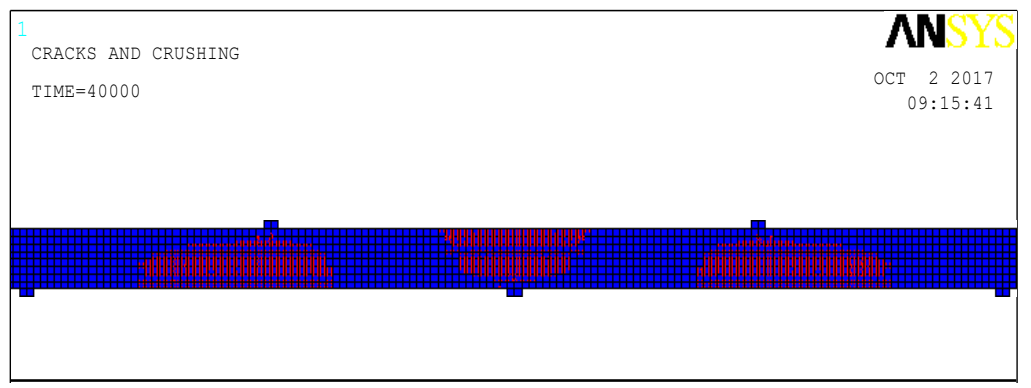

Figure 8 First cracks at a Load of $20 \mathrm{KN}$

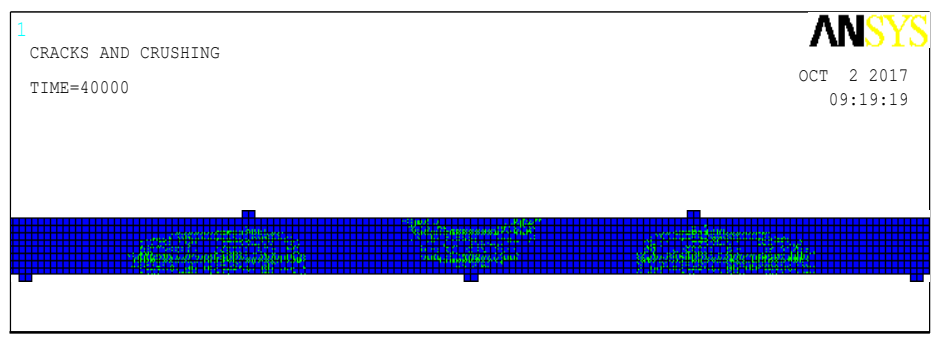

Figure 9 Second cracks at a Load of $20 \mathrm{KN}$

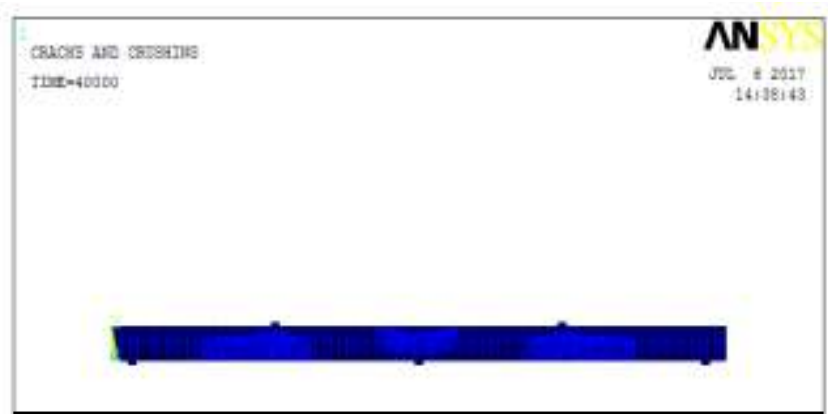

Figure 10 Third cracks at a Load of $20 \mathrm{KN}$

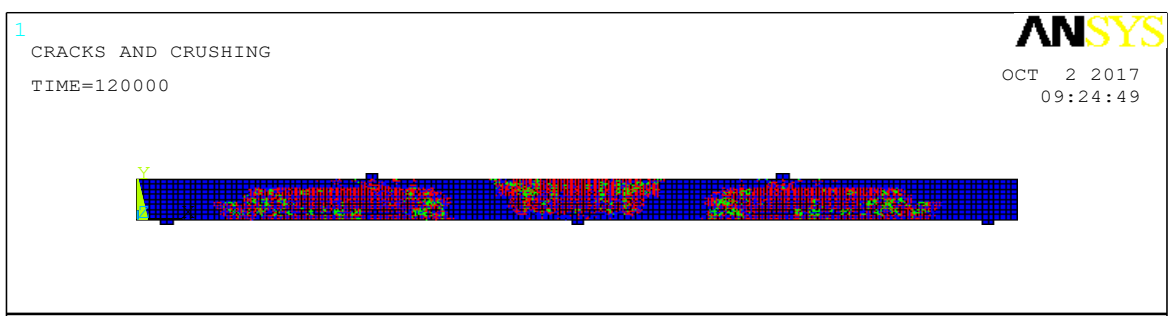

Figure 11 Crack pattern at failure

The below graphs will present the strain and the deflection produced from the ANSYS model along with the experimental work done by El-Mogy,M. (2011) for beam CS/e; their validation is shown in the following figures. 
Numerical and Analytical Evaluation of Continuous Concrete Beam Reinforced with FRP Bars

\subsubsection{Strain in the reinforcement}

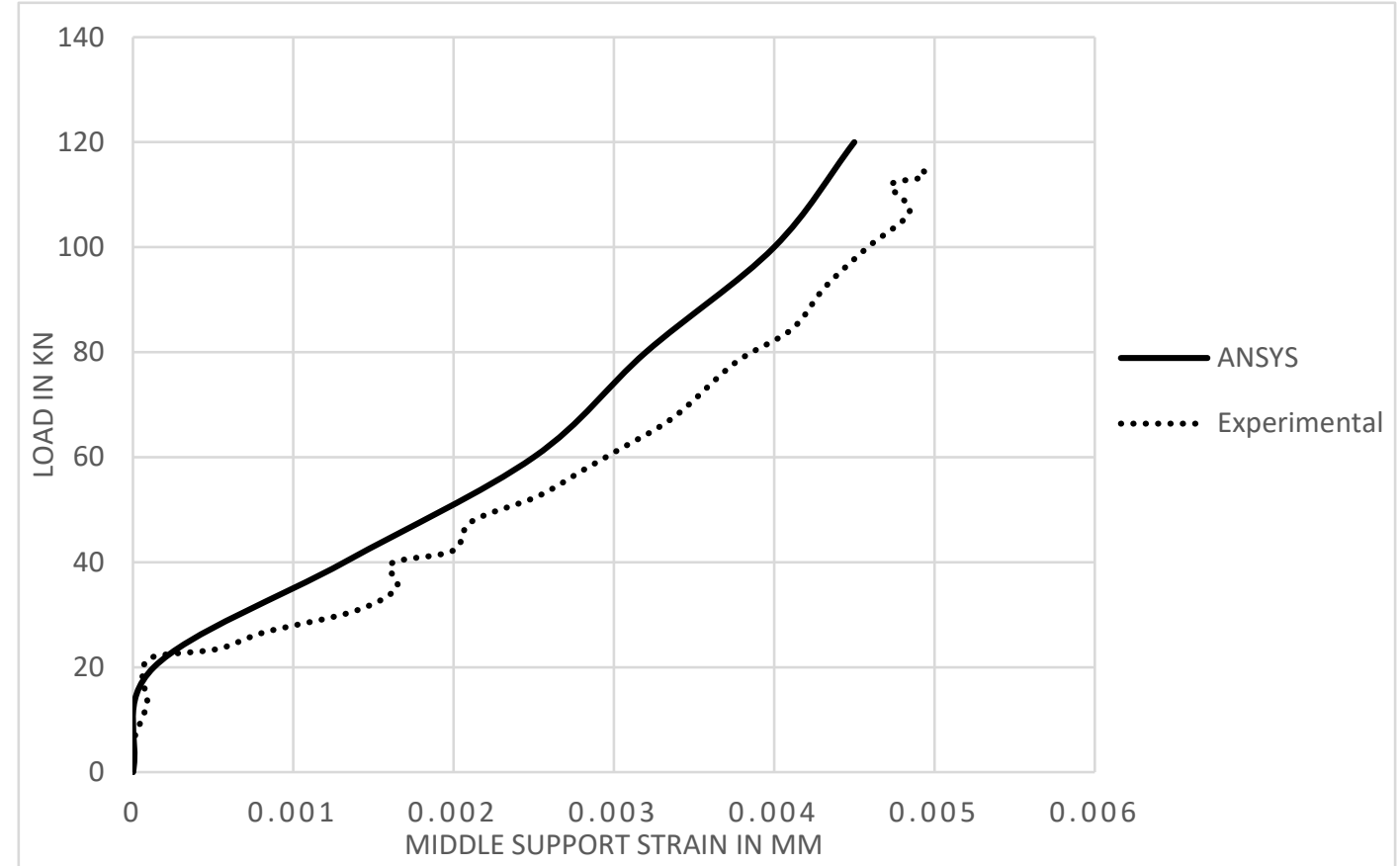

Figure 12 Load - strain curves of the ANSYS model and the experimental work for the top CFRP bars of beam CS/e

The strain that occurred in the upper reinforcement for beam CS/e on the ANSYS model reacted in the same manner as the experimental work with the largest gap between both curves at a load of $80 \mathrm{KN}$ with $18.7 \%$ percent difference.

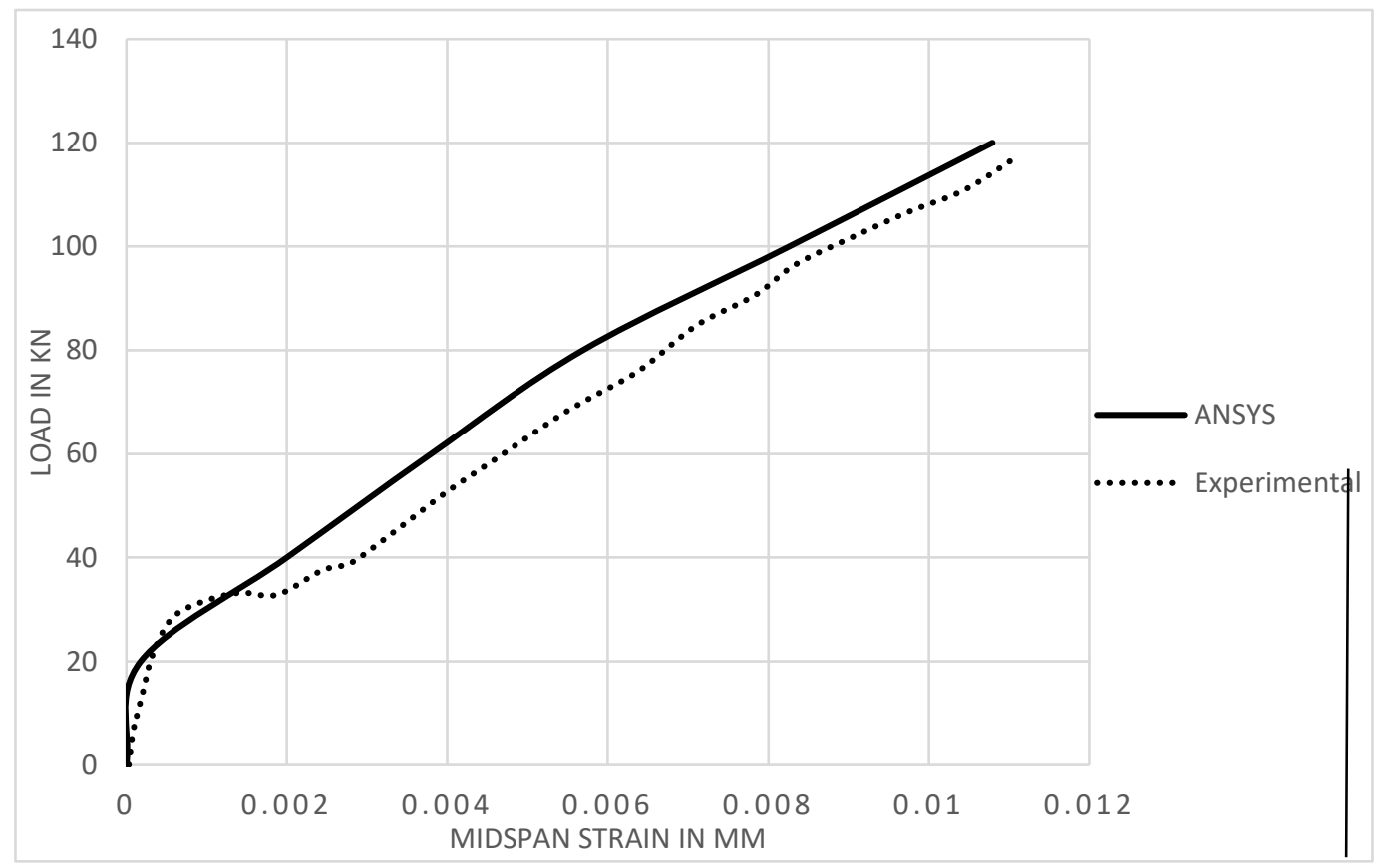

Figure 13 Load - strain curves of the ANSYS model and the experimental work for the bottom CFRP bars of beam CS/e

After observing the above graphs in Fig. (13), it seems that the ANSYS model has lower strain than the actual strain exerted from the experimental work. At a load of $40 \mathrm{KN}$, the above 
figure shows the largest gap between both graphs with approximately $20 \%$ difference in the strain of the ANSYS model from the real beam.

\subsubsection{Deflection}

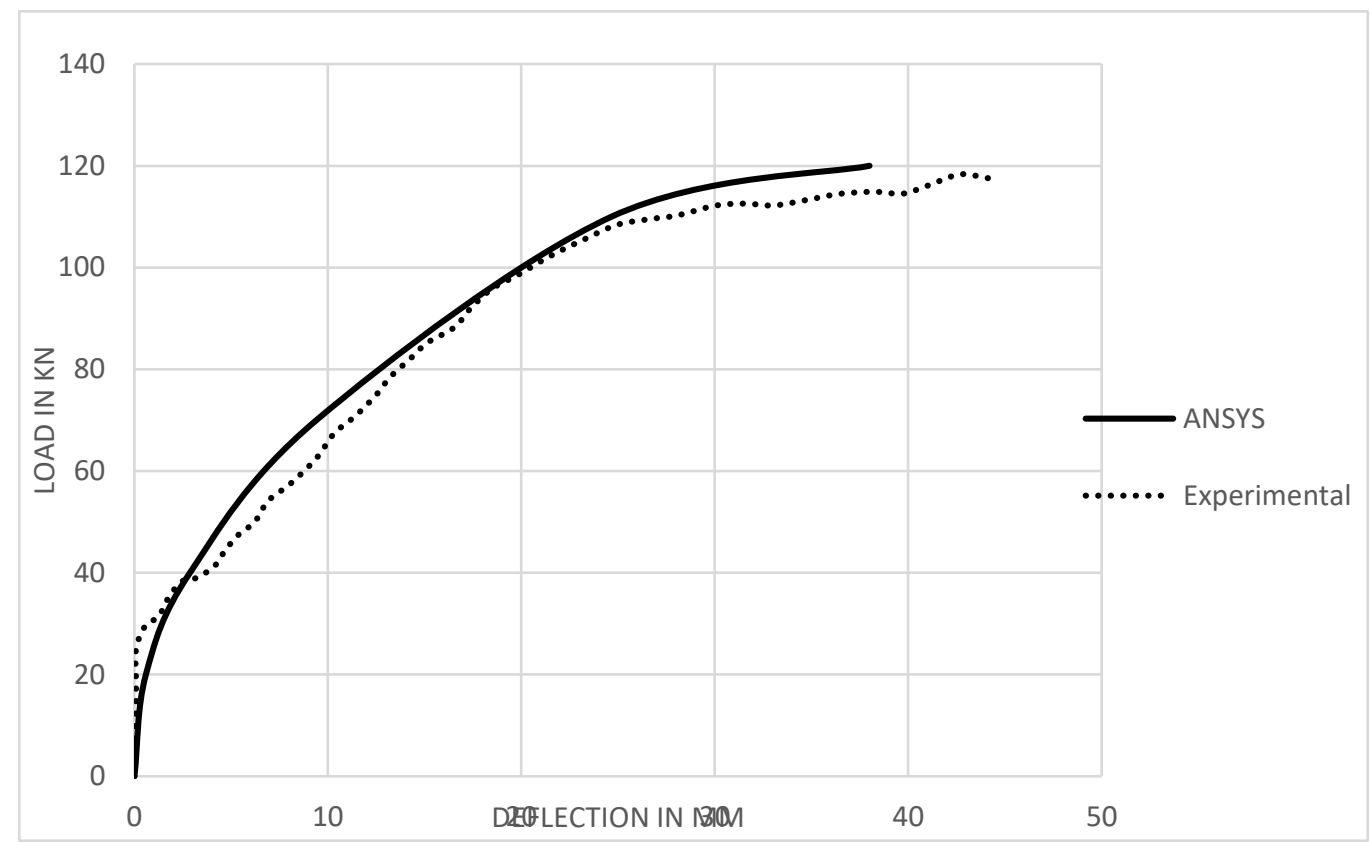

Figure 14 Load - deflection curves of the ANSYS model and the experimental work of CS/e

Based on the results shown in the above figure, the ANSYS model of beam CS/e sustained more load before it fails, the failure load resulted from the ANSYS is $120 \mathrm{KN}$ while the beam done in the experimental work done by El-Mogy,M. (2011) fails at 117 . KN creating a $2.2 \%$ difference between them.

\subsubsection{Validation of GS/e}

\subsubsection{Crack Pattern}

In beam GS/e, the first crack appeared at $13 \mathrm{KN}$ only at the middle support followed by cracks at midspan at a load of $20 \mathrm{KN}$ as mentioned in the study of El-Mogy, M.(2011), the following figures obtained from the ANSYS model showed exactly the same results for the cracks as the experimental study.

As shown in Fig. (15), at a load of $13 \mathrm{KN}$, the cracks only appeared at the middle support which is what was mentioned in the practical work.

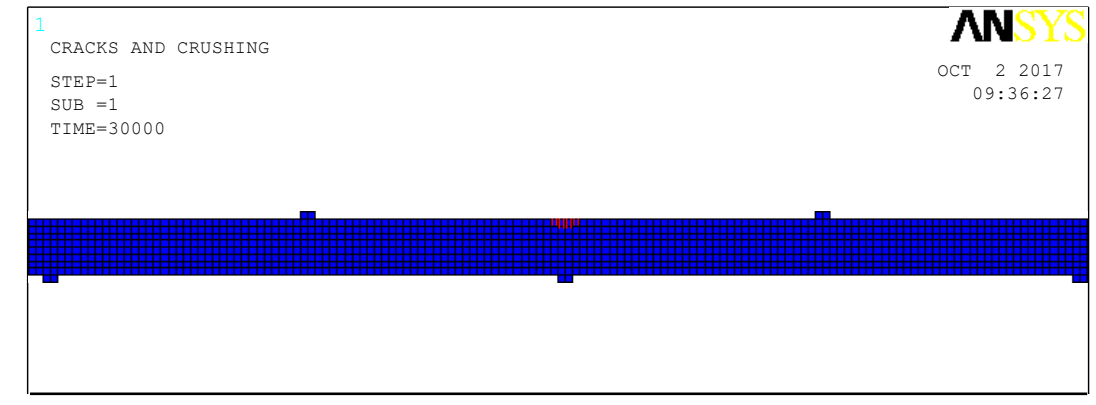

Figure 15 Middle support cracks at $13 \mathrm{KN}$ 
Numerical and Analytical Evaluation of Continuous Concrete Beam Reinforced with FRP Bars

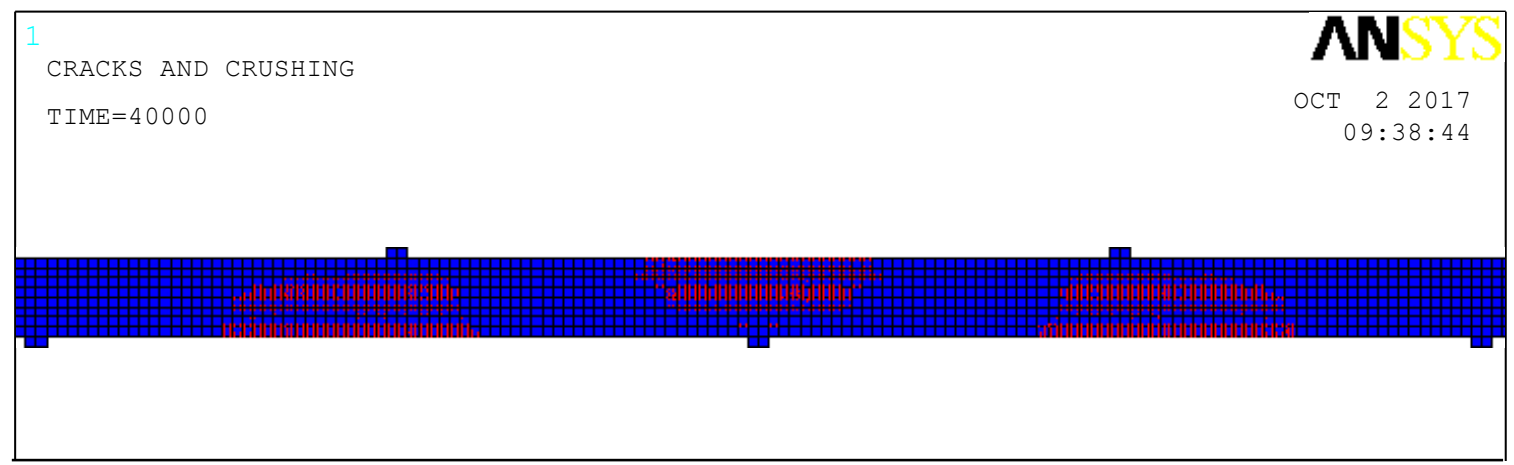

Figure 16 First cracks at a Load of $20 \mathrm{KN}$

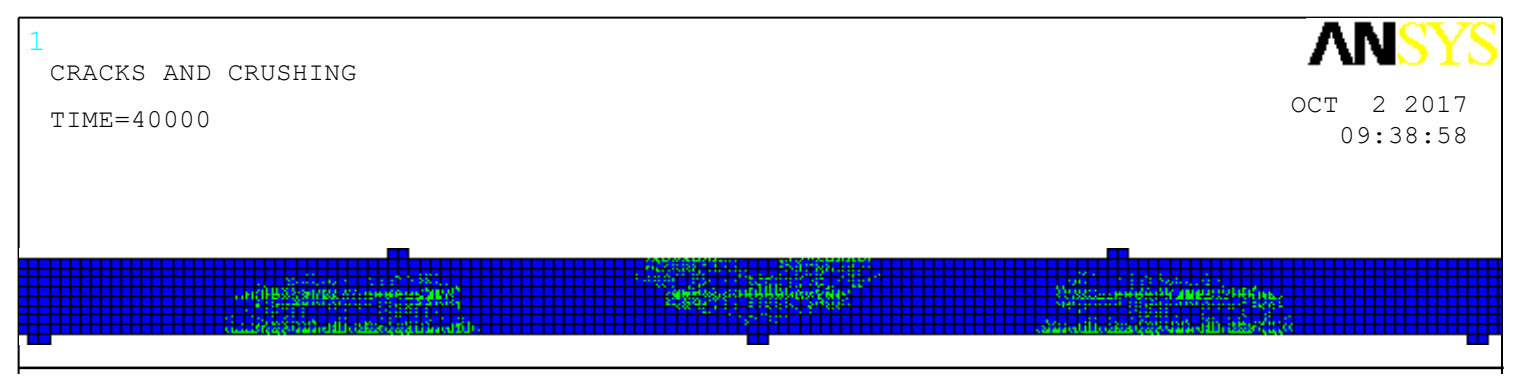

Figure 17 Second cracks at $20 \mathrm{KN}$

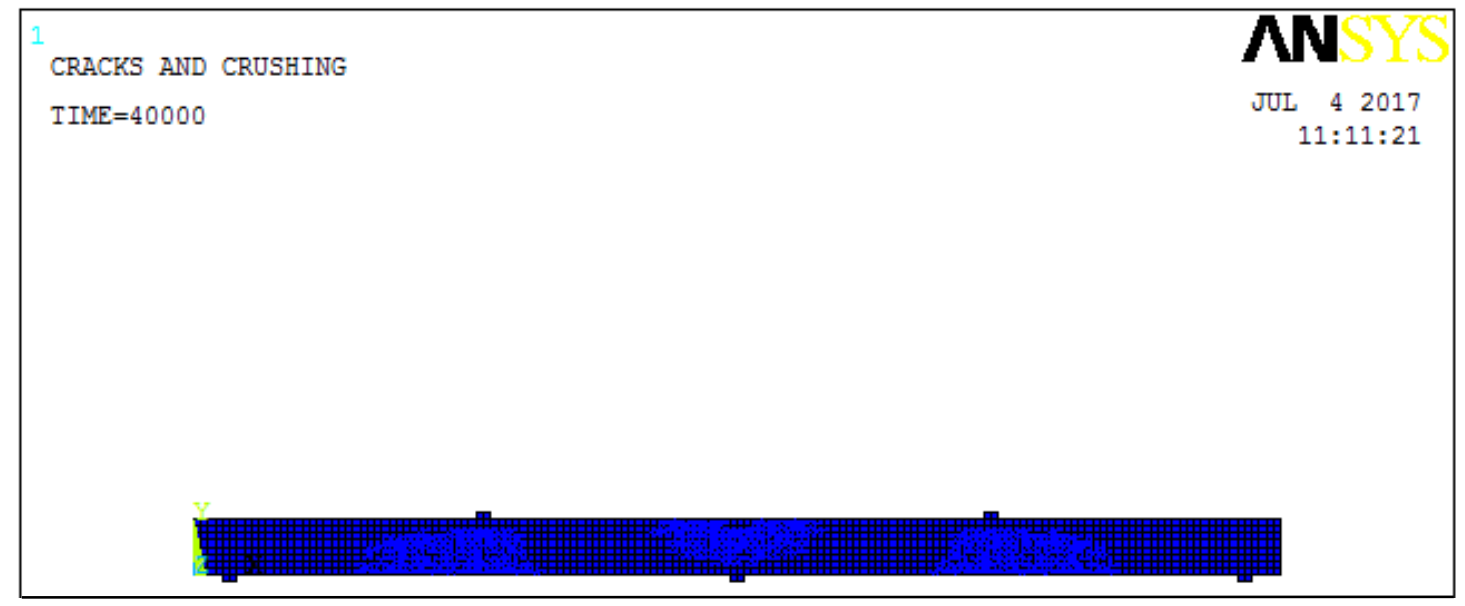

Figure 18 Third cracks at a Load of $20 \mathrm{KN}$

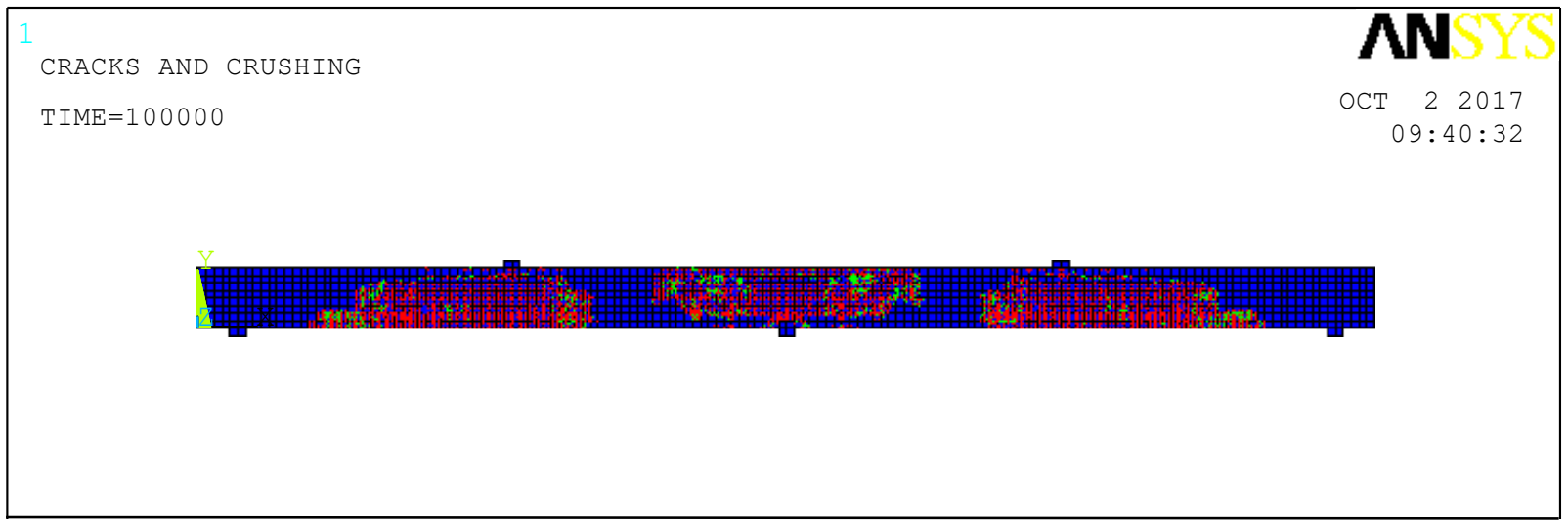

Figure 19 Crack pattern at failure 


\subsubsection{Strain in the Reinforcement}

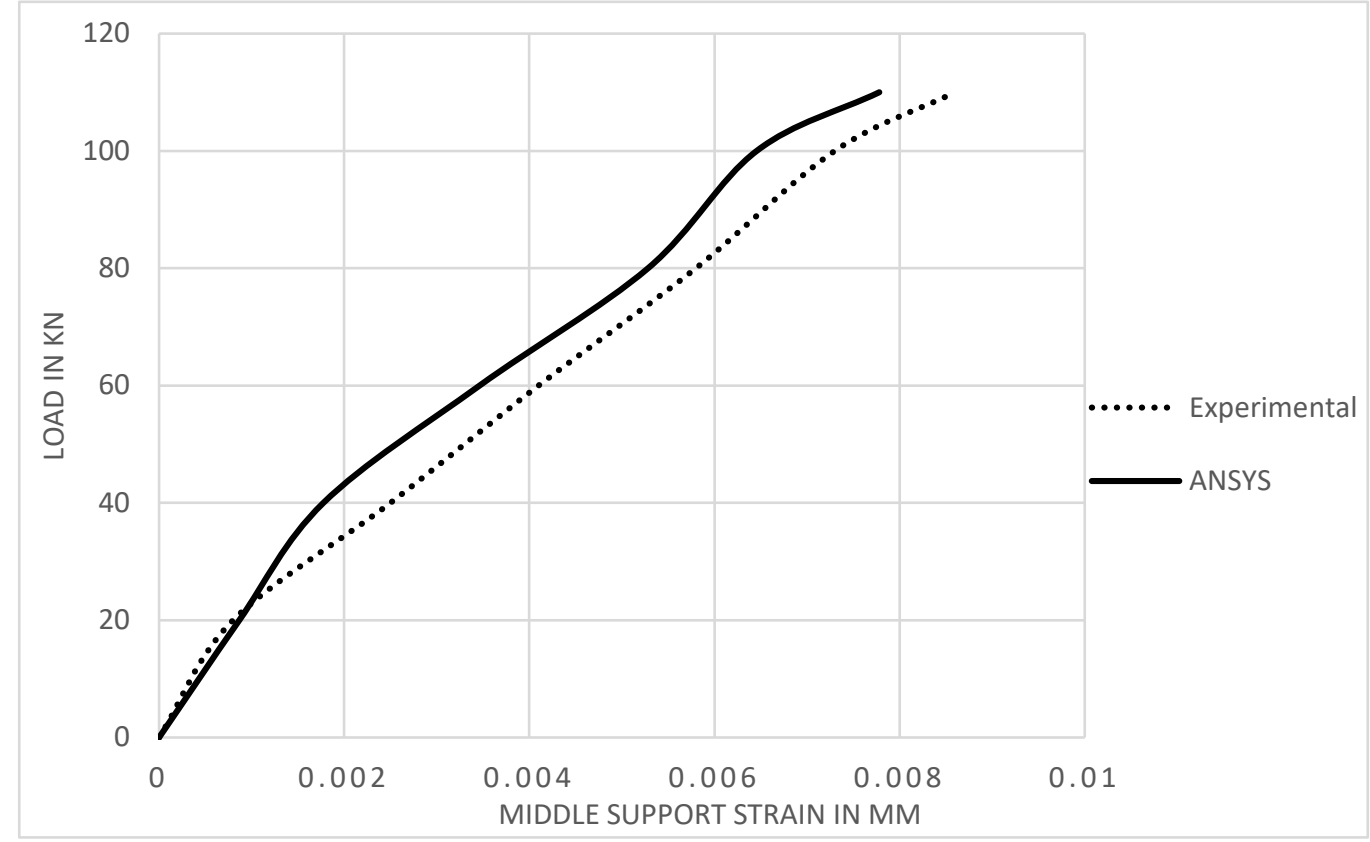

Figure 20 Load - stain curves of the ANSYS model and the experimental work for the top GFRP bars of beam GS/e

Fig. (20) demonstrates the strain produced in the upper Glass Fiber Reinforced bars due to the applied load, it is shown that the strains figured by ANSYS are in good consistency with those predicted by the experimental work. As it can be seen that at load $40 \mathrm{KN}$, the maximum deviation between both curves occurred with an average of 20 percent difference between them.

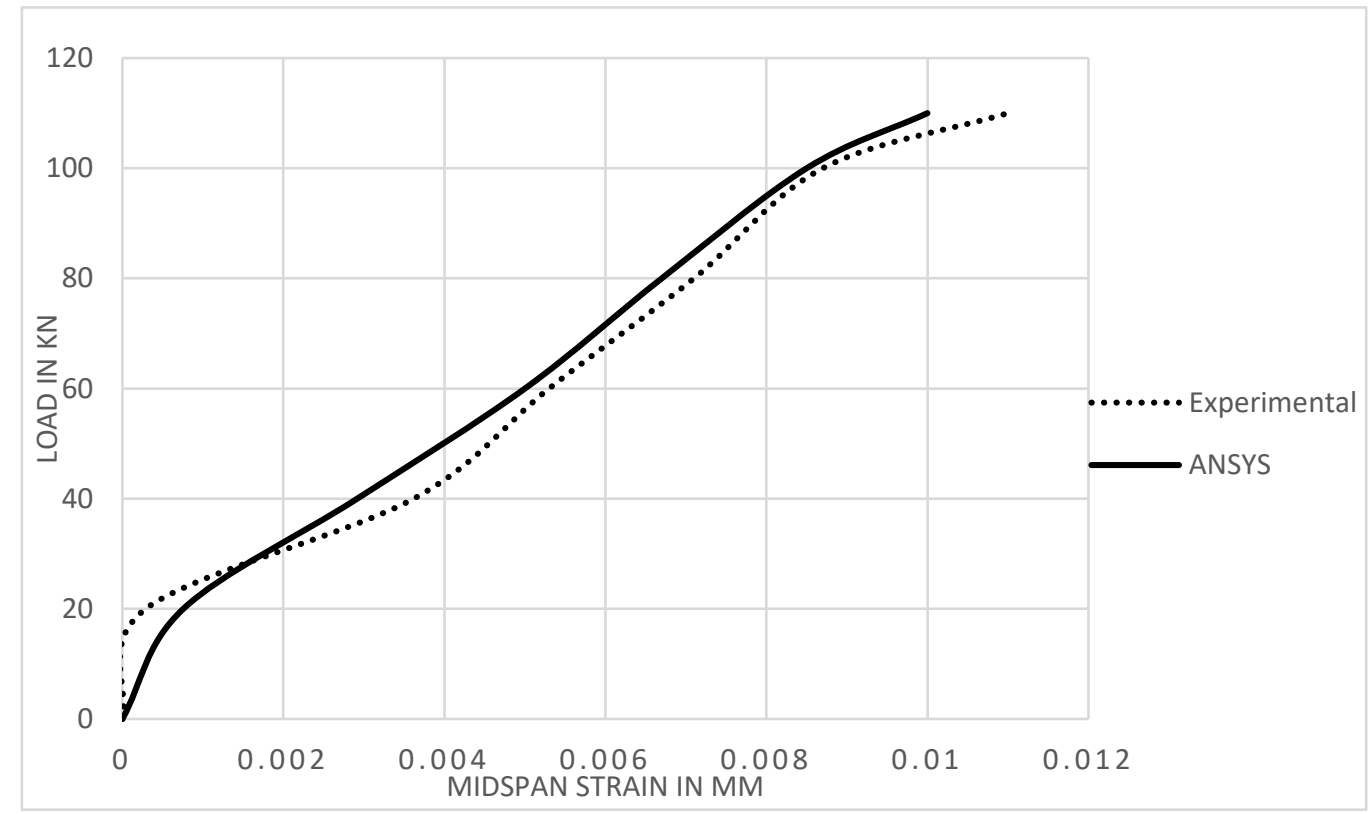

Figure 21 Load - stain curves of the ANSYS model and the experimental work for the bottom GFRP bars of beam GS/e

Fig. (21) shows the strain produced in the lower Glass Fiber Reinforced bars at the midspan due to the applied load. In the lower GFRP bars, the curves are much closer than the upper GFRP bars which means more accurate results appeared in the lower bars with a percentage of 
difference less than 20 percent at a load of $40 \mathrm{KN}$ which has the largest percentage of difference as shown in the above figure.

\subsubsection{Deflection}

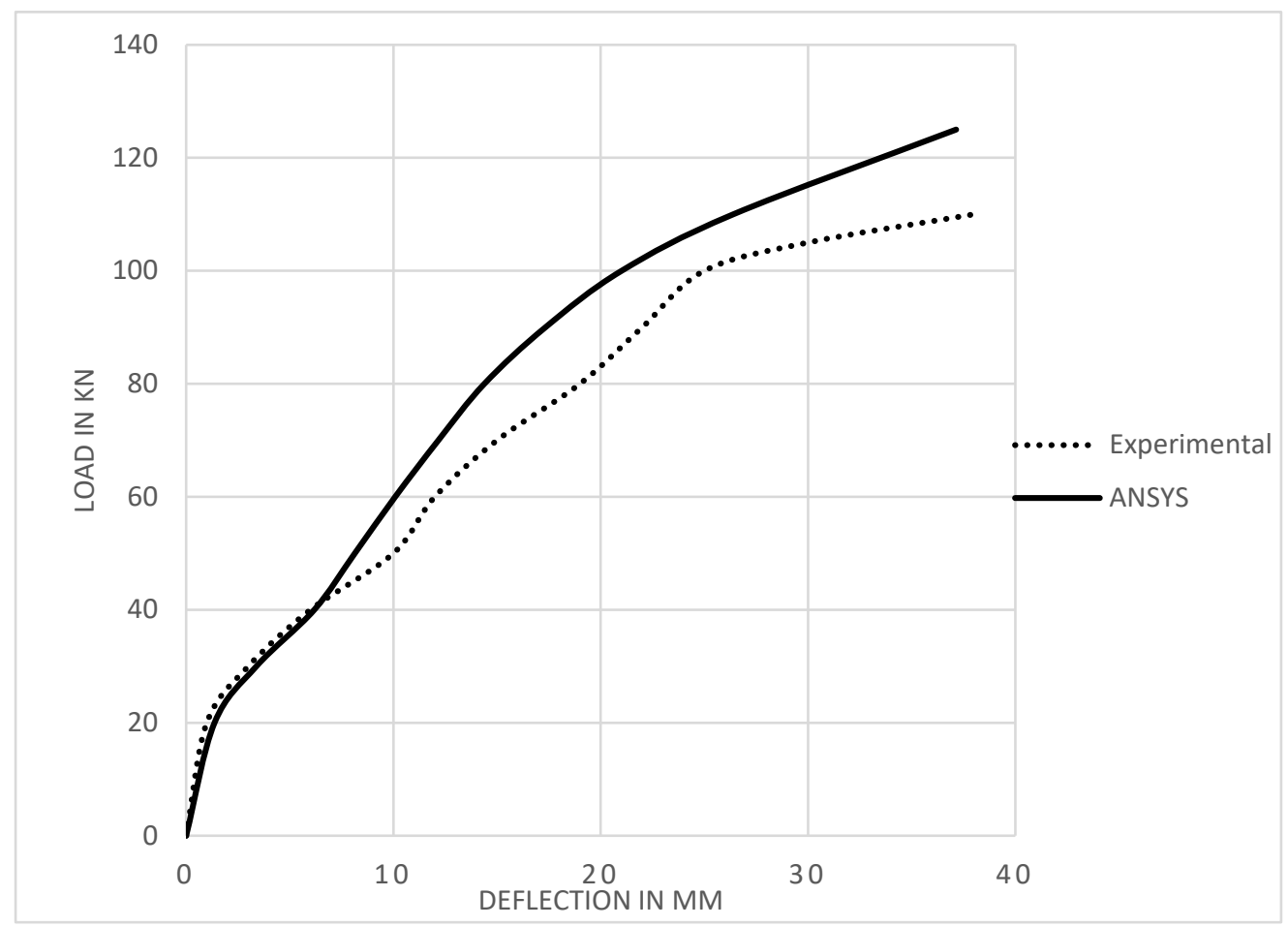

Figure 22 Load - deflection curves of the ANSYS model and the experimental work of GS/e

It can be shown in Fig. (22) that the difference between the deflection values calculated from the ANSYS model and the practical work lies in a very acceptable range; the two curves are very close until a load of $40 \mathrm{KN}$ is applied, both values are nearly the same at this point then afterwards, the curves start to diverge with a maximum deviation at $80 \mathrm{KN}$ of 20 percent difference between the ANSYS model and the experimental one.

The ANSYS model sustained more load than the experimental one, the maximum load applied on ANSYS is $125 \mathrm{KN}$ before failure of the beam while in the experimental model; it fails at $110 \mathrm{KN}$ with an average of 8 percent difference between both models.

\subsection{Summary}

All the above results of the ANSYS models shall increase the awareness in trusting the ANSYS software to analyze a continuous beam reinforced with FRP; the models held on the ANSYS is in good agreement with the experimental results which mean that the models constructed through the finite element package is uniquely verified; the difference between both models lies within a reasonable range.

The ANSYS models created to satisfy all of the above cases show that they have better results than the experimental beams; lower deflection and less strain values were produced from the ANSYS model as it is supposedly a perfect model with no human errors that occur unintentionally in the experimental work.

The finite element model represented in this study could foresee with an acceptable precision and accuracy the strain in the upper and lower reinforcements along with the deflection that occurs to a continuous beam while applying the load. Consequently, the finite element model will be used in representing the experimental part which will be used in this 
study along with the other codes (ECP, ACI and CSA) to compare the deflection of a continuous beam reinforced with different types of FRP.

To evaluate the performance of the continuous concrete beams reinforced with Fiber Reinforced Polymers and understand more about its behavior and the corresponding values resulted from the codes; The ECP, ACI and the CSA codes along with the ANSYS model are compared together in each of the above mentioned comparisons; crack widths and the deflection are calculated from each code and the ANSYS model to evaluate which of the codes yielded results close to reality and which shows a large deviation.

While comparing the codes when it comes to cracking; eyes should be kept open on the Egyptian code whether in the lower or the upper cracks as no empirical equations are presented in the code for that part; the rules used in this study are the same ones as that used with structures reinforced with Steel bars.

The below curves do not have the crack widths from the ANSYS model as the ANSYS model only shows the crack pattern presented previously but do not obtain crack widths' values.

\section{SERVICEABILITY LIMITS OF THE CHOSEN CODES}

\subsection{Crack width}

\subsubsection{ECP}

Crack width rules are not presented in The Egyptian Code for the use of Fiber Reinforced Polymer in the Construction Fields so it is assumed that it has the same concept as that presented in The Egyptian Code for the Design and Construction of Concrete Structures.

Crack width is not a major concern when it comes to FRP reinforcement due to its excellent corrosion resistance; the maximum crack width allowed in the Egyptian code for concrete structures reinforced with FRP is $\mathbf{0 . 5 0}$ mm (ECP 2005).

Crack width using the Egyptian code is calculated using the below rules (ECP 2007).

$$
\begin{aligned}
\mathrm{w}_{\mathrm{k}} & =\beta \times \mathrm{S}_{\mathrm{rm}} \times \varepsilon_{\mathrm{sm}} \leq \mathrm{w}_{\mathrm{kmax}} \ldots \\
\mathrm{S}_{\mathrm{rm}}=50 & +0.25 \times \mathrm{k}_{1} \times \mathrm{k}_{2} \times \frac{\boldsymbol{\phi}}{\boldsymbol{\rho r}} \ldots \ldots \ldots \ldots \\
\mathrm{Esm} & =\frac{\mathbf{f f}}{\mathbf{E f}}\left(\mathbf{1}-\boldsymbol{\beta 1} . \boldsymbol{\beta 2}\left(\frac{\mathbf{f f r}}{\mathbf{f f}}\right)^{\mathbf{2}}\right) .
\end{aligned}
$$

Where $\boldsymbol{\beta}$ is a coefficient that links between the designed crack width and the actual crack width, $\mathbf{S}_{\mathbf{r m}}$ is the average spacing between the cracks in $\mathrm{mm}$ and $\boldsymbol{\varepsilon}_{\mathbf{s m}}$ is the average tension strain in the rebars within the cracks spacing taking into account the strain in the concrete between the tension cracks.

$\boldsymbol{\beta}_{1}$ represents the bond properties of the bar used, $\boldsymbol{\beta}_{2}$ depends on the duration of the applied load (Ghoneim, M. et.al 2008).

k1 represents the bond between the bar and the concrete between the cracks while $\mathbf{k}_{2}$ depends on whether the section is subjected to pure bending or to pure axial tension (Ghoneim, M. et.al 2008).

$\boldsymbol{\phi}$ is the diameter of the bar used, $\boldsymbol{\rho}_{\mathbf{r}}$ is the Area of the tensile FRP bars divided by the effective area of the concrete section in tension (Ghoneim, M. et.al 2008).

$$
\rho_{\mathrm{r}}=\frac{\mathbf{A f}}{\text { Acef }}
$$

$\mathbf{f}_{\mathbf{f}}$ is the stress in the tensile FRP bars due to the permanent loads while $\mathbf{f}_{\mathbf{f r}}$ is the stress in the tensile FRP bars due to the crack load Mcr (Ghoneim, M. et.al 2008).

$$
\mathrm{f}_{\mathrm{f}}=\frac{\mathrm{nfrp} \times \operatorname{Mact}(\mathrm{d}-\mathrm{z})}{\text { Icr }}
$$




$$
\mathrm{f}_{\mathrm{fr}}=\frac{\mathbf{n f r p} \times \operatorname{Mcr}(\mathbf{d}-\mathbf{z})}{\mathbf{I c r}}
$$

\subsubsection{ACI}

The ACI code does not address the cracks with the direct crack calculation method; rather an indirect method is used to control the flexural cracks through a maximum reinforcing bar spacing using the following rule (ACI Committee 440, 2015):

$$
\mathrm{S}_{\max }=1.15 \times \frac{E f . w}{f f s . k b}-2.5 \mathrm{c}_{\mathrm{c}}
$$

Where $\mathbf{S}_{\max }$ is the maximum FRP bar spacing, $\mathbf{E}_{\mathbf{f}}$ is the modulus of elasticity of the FRP used, $\mathbf{w}$ is the crack width corresponding to the maximum bar spacing, $\mathbf{f}_{\mathbf{f s}}$ is the FRP stress at service which is calculated by evaluating a cracked elastic section analysis (ACI Committee 440, 2015):

$$
\mathrm{f}_{\mathrm{fs}}=\mathrm{M}_{\mathrm{s}} \times \frac{n f \cdot d(1-k)}{I c r} \equiv \mathrm{M}_{\mathrm{s}} \times \frac{n f(d-z)}{I c r}
$$

\subsubsection{CSA}

As for the Canadian code, the crack width is calculated using the following equation

$$
\mathrm{w}=2.2 \mathrm{~kb} \times \frac{f f r p}{E f r p} \times \frac{h 2}{h 1} \times(\text { dc. A })^{\frac{1}{3}}
$$

where $\mathbf{w}$ is the crack width in $\mathbf{m m}, \mathbf{k} \mathbf{b}$ is a coefficient that depends on the bond between the FRP and the concrete (it is the same as the $\mathrm{k}_{\mathrm{b}}$ explained earlier in the ACI code), $\mathbf{f}_{\text {frp }}$ is the stress in the FRP at the crack location, $\mathbf{h}_{\mathbf{2}}$ is the distance from the extreme tension edge to the neutral axis, $\mathbf{h}_{\mathbf{1}}$ is the distance from the centroid of the tension reinforcement to the neutral axis, $\mathbf{d}_{\mathbf{c}}$ is the concrete cover and $\mathbf{A}$ is the area with a centroid as that of the reinforcement divided by the number of bars (ISIS Canada 2007).

\subsection{Comparison Between the Codes and the ANSYS Model}

\subsubsection{Upper cracks}

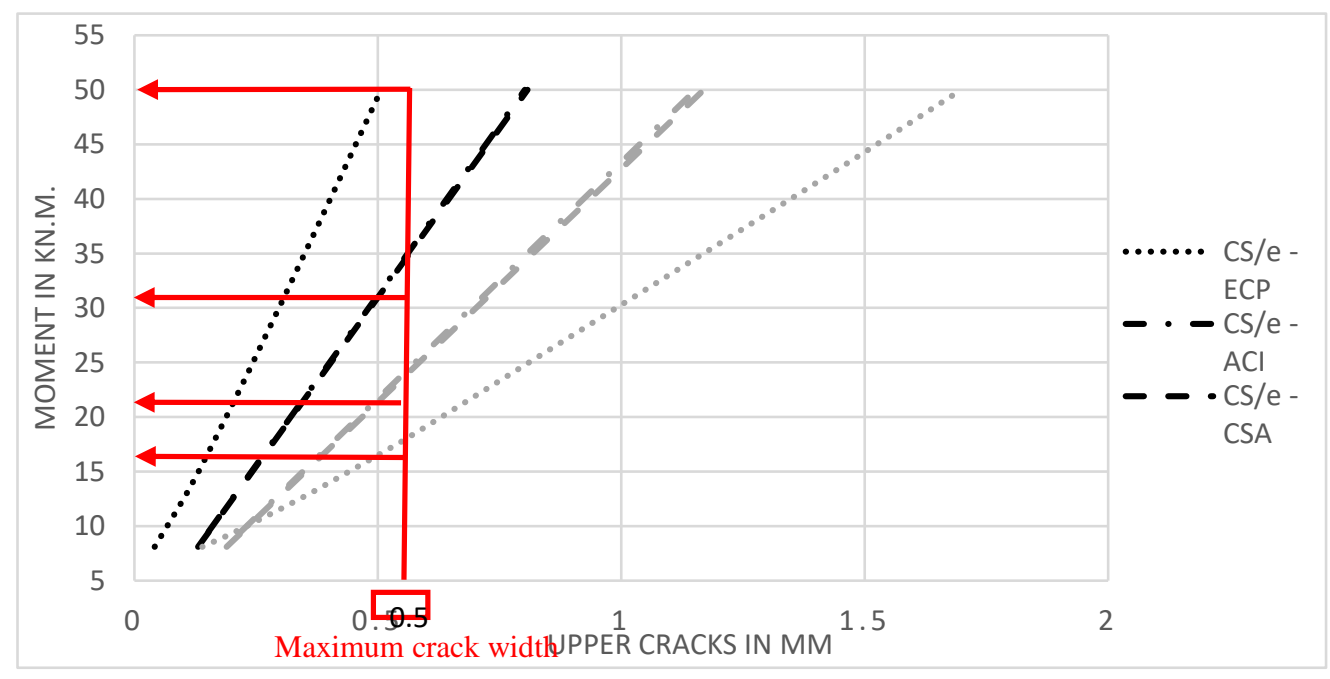

Figure 23 Codes' comparison for the upper cracks at the maximum crack width

CS/e has lower crack widths at the middle support and that is due to the fact that it has four CFRP bars in the upper reinforcement while beam GS/e has three bars. In both beams, the Canadian and the American codes are seen as a single line as they have the same values for the upper crack widths unlike the Egyptian code that showed a large difference in the results than the other codes; that difference could be anticipated as there are no rules written specifically for 
the FRP, same rules as that of the Steel were used and that can lead to errors and inaccuracy in the results as the FRP and the Steel behave in a different manner.

Table 3 Moment at the maximum crack width at the middle support

\begin{tabular}{|c|c|c|}
\hline \multirow{2}{*}{ Codes } & \multicolumn{2}{|c|}{$\begin{array}{c}\text { Moment in KN.m corresponding to the maximum crack width } \\
\mathbf{( 0 . 5} \mathbf{~ m m})\end{array}$} \\
\cline { 2 - 3 } & CS/e & GS/e \\
\hline Egyptian ECP code & 49.500 & 16.700 \\
\hline American ACI code & 31.390 & 21.820 \\
\hline Canadian CSA code & 31.050 & 21.520 \\
\hline \hline Average & 37.313 & 20.013 \\
\hline Standard deviation & 8.618 & 2.346 \\
\hline $\begin{array}{c}\text { Coefficient of } \\
\text { Variation }\end{array}$ & 23.097 & 11.797 \\
\hline
\end{tabular}

The above table shows the moment applied that produces the maximum crack widths allowed in the codes; the ECP code states that the maximum allowed crack width is $0.5 \mathrm{~mm}$ (ECP 2005) while the ACI sets a range for the maximum crack width between $0.4 \mathrm{~mm}$ till 0.7 mm (ACI Committee 440, 2015) and the CSA code has the same limit as the Egyptian code so for the comparison purpose; a maximum crack width of $0.5 \mathrm{~mm}$ is used as it satisfies all the used codes' limits (ISIS Canada 2007).

TABLE (3) assures that the Canadian and the American codes whether in the Carbon or Glass Fiber Reinforced Polymer beam have approximately the same results with $1.5 \%$ difference between them while the Egyptian code produced 57\% difference than the other codes in beam CS/e and 23\% difference in beam GS/e leading to an unacceptable percent in both beams; it is obvious whether with the graphical representation or with numerical method that the Egyptian code's results are far from the other used codes.

Since the ACI is out from the comparison in the maximum crack width, the ECP and the CSA are the only comparable ones with an unacceptable deviation occurs between the CSA and the ECP code. The coefficient of Variation in CS/e beam for the moment at the maximum crack width lies with an acceptable range of less than $25 \%$ while in the GS/e, the Egyptian code is outside the normal range of the standard deviation method by $6 \%$.

The other point for comparison is the crack width that is created at the cracking moment.

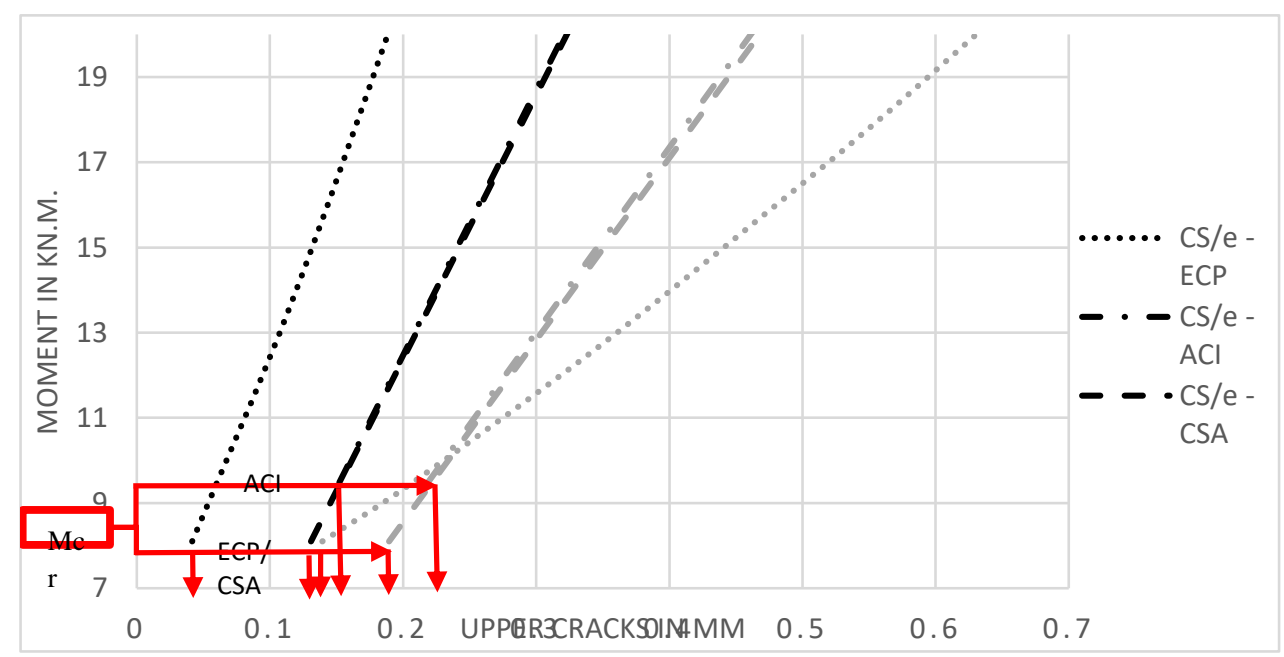

Figure 24 Codes' comparison for the upper cracks at the cracking moment 
TABLE (4) represents the crack width at the cracking load/moment; the cracking moment for the Egyptian and the Canadian codes $\left(\right.$ Mcr $=$ fctr $\left.\times \frac{I g}{\bar{y}}\right)$ differs than the American code $\left(\operatorname{Mcr}=\frac{0.62 \cdot \lambda \cdot \sqrt{f c^{*}} \cdot I g}{y t}\right)$.

Foe beam CS/e, as it is shown from the values obtained from TABLE(4) after calculating the standard deviation that all the codes lie within the normal range except the Egyptian code, it is below the normal accepted values. The standard deviation reached more than $40 \%$ in beam CS/e.

The Canadian code in GS/e lies within the range calculated by the standard deviation method while the Egyptian code has a $6 \%$ difference than the standard deviation range for beam GS/e. Also the American code is not in the range with a maximum of $7 \%$ difference.

Table 4 Crack Width at the cracking moment at the middle support

\begin{tabular}{|c|c|c|}
\hline \multirow{2}{*}{ Codes } & \multicolumn{2}{|c|}{ Crack width in mm obtained at the cracking moment } \\
\cline { 2 - 3 } & CS/e & GS/e \\
\hline Egyptian ECP code & 0.042 & 0.139 \\
\hline American ACI code & 0.152 & 0.219 \\
\hline Canadian CSA code & 0.131 & 0.189 \\
\hline \hline Average & 0.108 & 0.182 \\
\hline Standard deviation & 0.048 & 0.033 \\
\hline Coefficient of Variation & 44.444 & 18.132 \\
\hline
\end{tabular}

Same conclusions are made in beam CS/e which states that the Egyptian code lies outside the range calculated by the standard deviation method but in beam GS/e, the American code along with the Egyptian code are outside the norm. The above tables show that all the coefficient of variation in all the tested beams are less than $20 \%$.

\subsubsection{Lower cracks}

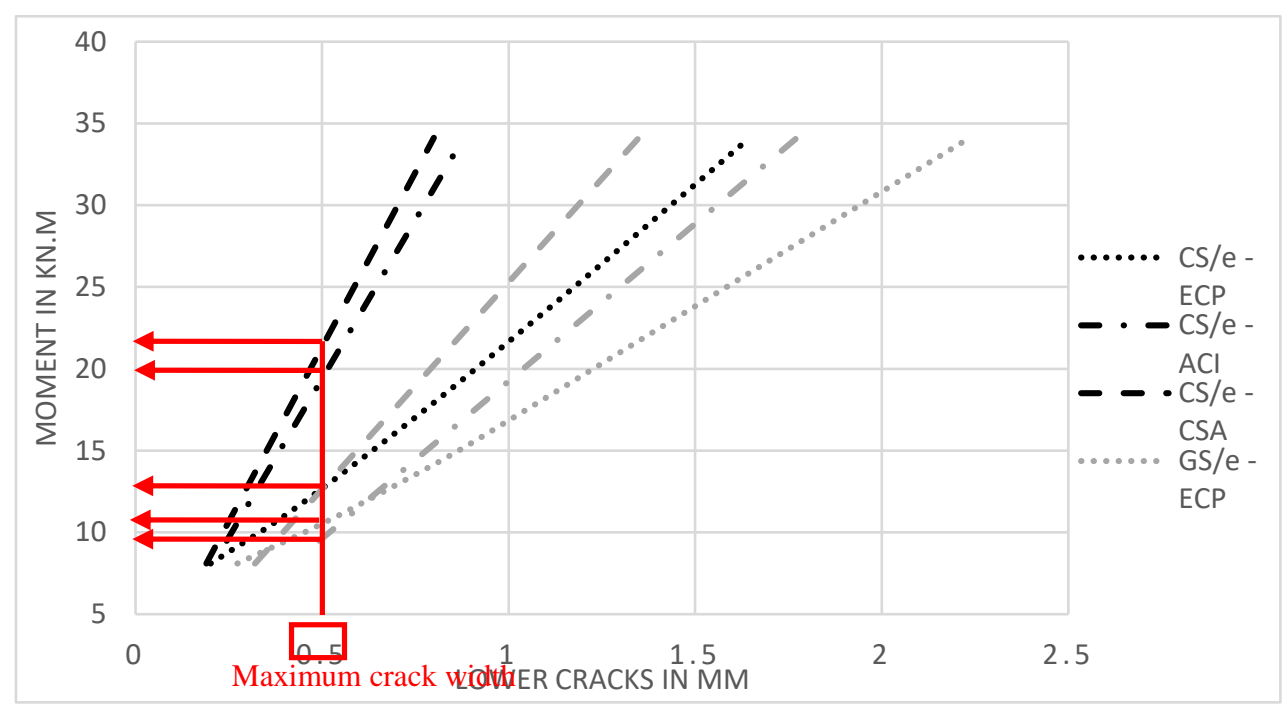

Figure 25 Codes' comparison for the lower/midspan cracks at the maximum crack width

The same behavior continues in the lower cracks; in beam CS/e, the Egyptian code has large crack widths when compared to the other codes which results are close but not identical as shown in the previous curves. In beam GS/e; unexpected behavior occurred, all the codes have different results leading to large gap between their curves. 
Table 5 Moment at the maximum crack width at the mid span

\begin{tabular}{|c|c|c|}
\hline \multirow{2}{*}{ Codes } & \multicolumn{2}{|c|}{$\begin{array}{c}\text { Moment in KN.m corresponding to the maximum crack width } \\
(\mathbf{0 . 5} \mathbf{~ m m})\end{array}$} \\
\cline { 2 - 3 } & $\mathbf{C S / e}$ & GS/e \\
\hline Egyptian ECP code & 12.650 & 10.550 \\
\hline American ACI code & 19.400 & 9.650 \\
\hline Canadian CSA code & 21.300 & 12.900 \\
\hline \hline Average & 17.783 & 11.033 \\
\hline Standard deviation & 3.712 & 1.370 \\
\hline Coefficient of Variation & 20.874 & 12.417 \\
\hline
\end{tabular}

TABLE (5) shows that in beam CS/e, the Egyptian code lies outside the normal range with a $34 \%$ difference than the American code and $41 \%$ than the Canadian code. The American and the Canadian code lies within the normal range with $9 \%$ difference between the moments at the maximum crack width of $0.5 \mathrm{~mm}$. In beam GS/e, both the American and the Canadian codes are the ones that lie outside the standard deviation range, the American code has the lowest moment at the maximum crack width followed by the Egyptian code then the Canadian code.

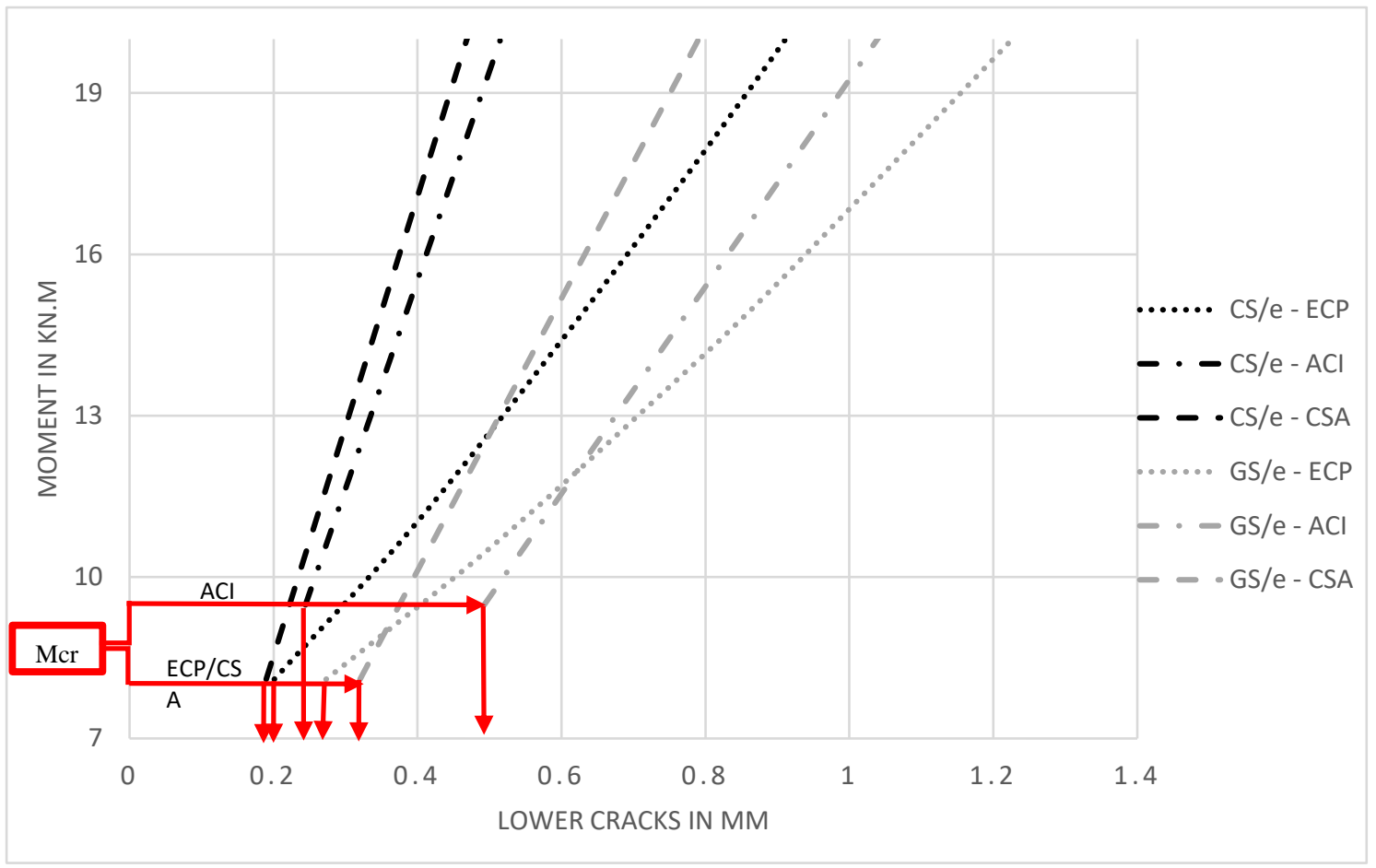

Figure 26 Codes' comparison for the lower/midspan cracks at the cracking moment

Table 6 Crack Width at the cracking moment at the midspan

\begin{tabular}{|c|c|c|}
\hline \multirow{2}{*}{ Codes } & \multicolumn{2}{|c|}{ Crack width in mm obtained at the cracking moment } \\
\cline { 2 - 3 } Egyptian ECP code & CS/e & GS/e \\
\hline American ACI code & 0.201 & 0.273 \\
\hline Canadian CSA code & 0.244 & 0.493 \\
\hline \hline Average & 0.190 & 0.320 \\
\hline Standard deviation & 0.217 & 0.362 \\
\hline $\begin{array}{c}\text { Coefficient of } \\
\text { Variation }\end{array}$ & 0.023 & 0.095 \\
\hline
\end{tabular}


As shown in TABLE (6), Beam CS/e has lower crack widths at the cracking moment in all the codes as the Carbon is stiffer than the Glass FRP since the lower reinforcement at the midspan of beam CS/e is higher than beam GS/e.

In the Carbon reinforced beams, approximately all the codes' results are within the range while in beam GS/e, the American code is the only one that lies outside the range with $8 \%$ variance.

\subsubsection{Deflection}

Instantaneous deflections of concrete structures reinforced with FRP can be calculated with several structural analysis methods; deflection using virtual work method is used in the three codes presented in this research.

$$
\delta=\frac{1}{E c . I e}(200083333.4 \mathrm{P})
$$

Where $\mathbf{E}_{\mathbf{c}}$ is the modulus of elasticity of the concrete and $\mathbf{I}_{\mathbf{e}}$ is the effective moment of inertia; each code calculates those two parameters using different equations.

The Egyptian code recommends that for the continuous beams, the effective moment of inertia will be the average of the effective moment of inertia at the maximum positive and the negative moments. When the beam is reinforced with CFRP bars, the stress should be limited to $65 \%$ of the ultimate stress so those values of the moment will be multiplied by 0.65 to satisfy the serviceability requirements and the serviceability requirement for the Glass Fiber Reinforced Polymers is $30 \%$ of the ultimate stress.

The effective inertia is calculated at both the maximum and the minimum moment to get the average between both of them (ISIS Canada 2007).

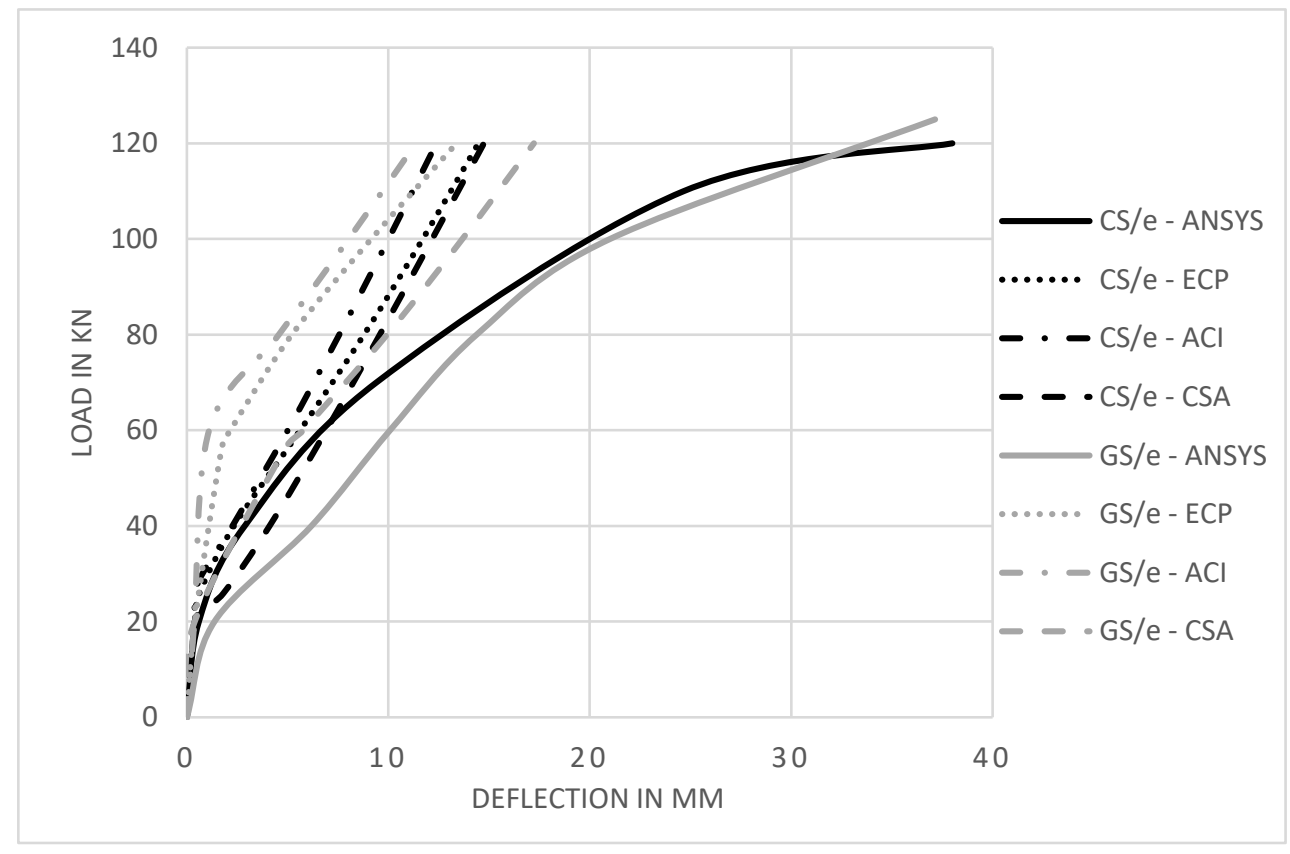

Figure 27 Codes' comparison for the deflection with the ANSYS model

The above graph shows that the codes' results are not the same as the ANSYS model which represents what happened in the experimental work. The ANSYS model showed lower deflection values in beam CS/e than beam GS/e but the deflection calculated using the various codes opposes the ANSYS models' results. All the codes have lower deflection values in the Glass reinforced beam than the Carbon reinforced beam. 
Aya Belal, Amr Elnemr and Nagy F.Hanna

Table 7 Deflection values at $0.67 \mathrm{M}_{\mathrm{n}}$

\begin{tabular}{|c|c|c|}
\hline \multirow{2}{*}{} & \multicolumn{2}{|c|}{ Deflection in $\mathbf{~ m m}$ at $\mathbf{~ 0 . 6 7 M}_{\mathbf{n}}$} \\
\cline { 2 - 3 } & $\mathbf{C S} / \mathbf{e}$ & $\mathbf{G S / e}$ \\
\hline Egyptian code & 10.475 & 13.114 \\
\hline American code & 9.036 & 10.686 \\
\hline Canadian code & 11.128 & 13.811 \\
\hline ANSYS model & 6.125 & 10.125 \\
\hline \hline Average & 9.191 & 11.934 \\
\hline Standard Deviation & 1.925 & 1.561 \\
\hline Coefficient of Variation & 20.944 & 13.080 \\
\hline
\end{tabular}

Comparison between both beams cannot be done at the serviceability limit as the Carbon is limited to 0.65 of its tensile strength and the Glass is limited to only 0.3 so the comparison is not adequate.

In TABLE (7), contradictory observation is noticed. Beam CS/e has lower deflection values than beam GS/e exactly like the ANSYS model which has higher deflection values in the Glass Fiber Reinforced beam than the Carbon one; that could be predicted as the Carbon bars are stiffer than the Glass ones and there are larger number of bottom reinforcement in beam CS/e than beam GS/e. That is why the graphical presentation is not enough for comparing between beams; certain points are needed to accurately compare with the exact values.

\section{CONCLUSIONS}

After all the codes were compared together along with the ANSYS model and the practical work done by El-Mogy,M. (2011) to analyze the crack widths and the deflection of the used beams in this study, the results showed the following:

- In the cracks whether the appeared upper or the lower ones; the Egyptian code's results are way far from the Canadian and the American codes and that could be due to the lack of crack widths' equations in the Egyptian code. The Egyptian code has to be updated when it comes to the crack widths as the results are not acceptable with a variance of 50 $\%$ than the other codes; consequently, it could not be relied on. Rules should be added for calculating the cracks in the ECP code.

- The Canadian and the American codes showed also a little variation of $2 \%$ averagely from the standard deviation range but in certain cases (in the lower cracks of beam GS/e only) as explained earlier but not in every case as the Egyptian code.

- The first conclusion stated whether the codes produced precise values or not but their accuracy has not been defined yet. All the codes succeed in producing accurate results except when comparing the beams that experienced moment redistribution; the Carbon reinforced beam should have lower cracks than the Glass reinforced one but all the codes' results do not agree with that whether in the upper or the lower cracks except the Canadian code in the lower cracks.

- When the deflection values were compared together, the results showed that all the values were acceptably precise but were not accurate when compared to the practical work. The three codes resulted in deflections near to the practical work at the beginning of loading but as the load applied increased, the deflection values started to vary from the real continuous beam with a maximum variance of $200 \%$ yielded by the Canadian code and the results started to be inaccurate approving that the three codes yield results that are far away from the Finite Element Model which represents the 
experimental/practical work done by El-Mogy,M. (2011) based on the standard deviation method.

- Despite the fact that the codes' results are far from the ANSYS model; when two beams are compared together in any case of the comparisons explained before, the codes' results agrees with the ANSYS results in the comparison except when the Glass reinforced concrete beams were compared together.

- In all the comparisons, the American code has the closest results to the experimental one then the Egyptian followed by the Canadian code.

\section{REFERENCES}

[1] El-Mogy,M. (2011). "Behaviour of Continuous Concrete Beams Reinforced with FRP Bars" (Doctoral thesis). University of Manitoba, Winnipeg, Manitoba, Canada. Retrieved from https://mspace.lib.umanitoba.ca/bitstream/handle/1993/4993/El-

Mogy_Mostafa.pdf?sequence $=1$.

[2] FRP Reinforcement Engineering (2017) Retrieved from http://www.build-on-prince.com/frpreinforcement.html\#sthash.WkRuP0ns.dpbs. May 29, 2017.

[3] El-Mogy, M., El-Ragaby, A. and El-Salakawy, E.F. (2010). "Behavior of Continuous Concrete Beams Reinforced with FRP Bars", The 5th International Conference on FRP Composites in Civil Engineering, Beijing, China, September 27-29.

[4] ANSYS (2015). Finite Element Analysis System [Computer Software].

[5] ECP. (2007). "Egyptian Code for Design and Construction of Concrete Structures", ECP 2032007, Egyptian Code of Practice.

[6] ACI Committee 440. (2015). "Guide for the Design and Construction of Structural Concrete Reinforced with Fiber-Reinforced Polymer (FRP) Bars”, ACI 440.1R-15, American Concrete Institute, Farmington Hills, Mich.

[7] ECP. (2005). "Egyptian Code of Practice for the Use of Fiber Reinforced Polymer (FRP) in the Construction Fields", ECP 208-2005, Egyptian Code of Practice.

[8] Ghoneim, M. and El-Mihilmy, M. (2008). "Design of Reinforced Concrete Structures", Vol.3. Egypt.

[9] ISIS Canada. (2007). "Design Manual 3, Reinforcing Concrete Structures with Fiber Reinforced Polymers (FRPs)", ISIS Canada Corporation, The Canadian Network of Centers of Excellence on Intelligent Sensing for Innovative Structures, Winnipeg, Manitoba, Canada. 